\title{
Sustained favorable long-term outcome in the treatment of schizophrenia: a 3-year prospective observational study
}

\author{
Gebra B Cuyún Carter*, Denái R Milton, Haya Ascher-Svanum and Douglas E Faries
}

\begin{abstract}
Background: This study of chronically ill patients with schizophrenia aimed to identify patients who achieve sustained favorable long-term outcome - when the outcome incorporates severity of symptoms, level of functioning, and use of acute care services - and to identify the best baseline predictors of achieving this sustained favorable long-term outcome.

Methods: Using data from the United States Schizophrenia Care and Assessment Program (US-SCAP) $(N=2327)$, a large 3-year prospective, multisite, observational study of individuals treated for schizophrenia in the US, a hierarchical cluster analysis was performed to group patients based upon baseline symptom severity. Symptom severity was assessed using the Positive and Negative Syndrome Scale (PANSS) scores, level of functioning, and use of acute care services. Level of functioning reflected patient-reported productivity and clinician-rated occupational role functioning. Use of acute care services reflected self-reported psychiatric hospitalization and emergency service use. Change of health state was determined over the 3-year period. A patient was classified as having a sustained favorable long-term outcome if their health state values had the closest distance to the defined "best baseline cluster" at each point over the length of the study. Stepwise logistic regression was used to determine baseline predictors of sustained favorable long-term outcome.
\end{abstract}

Results: At baseline, 5 distinct health state clusters were identified, ranging from "best" to "worst." Of 1635 patients with sufficient data, only 157 (10\%) experienced sustained favorable long-term outcome during the 2-years postbaseline. The baseline predictors associated with sustained favorable long-term outcome included better quality of life, more daily activities, patient-reported clearer thinking from medication, better global functioning, being employed, not being a victim of a crime, not having received individual therapy, and not having received help with shopping and leisure activities.

Conclusions: Only a small percentage of patients achieved sustained favorable long-term outcome in this study, suggesting there continues to be a great need for improvement in the treatment of schizophrenia. Findings suggest that clinicians could make early projections of health states and identify those patients more likely to achieve favorable long-term outcomes enabling early therapeutic interventions to enhance benefits for patients.

\section{Background}

Heterogeneity of response and outcome is common among patients treated for schizophrenia [1]. Clinical study results indicate that about $70 \%$ of patients fail to experience at least minimal efficacy early in treatment $[2,3]$, and current medications are effective for

\footnotetext{
* Correspondence: cuyun_carter_gebra@lilly.com
All authors are employees of Eli Lilly and Company, Global Health Outcomes;

* Correspondence: cuyun_carter_gebra@iilly.com
All authors are employees of Eli Lilly and Company, Global Health Outcomes; Indianapolis, IN, USA 46285
}

(C) 2011 Cuyún Carter et al; licensee BioMed Central Ltd. This is an Open Access article distributed under the terms of the Creative Commons Attribution License (http://creativecommons.org/licenses/by/2.0), which permits unrestricted use, distribution, and reproduction in any medium, provided the original work is properly cited. approximately $50 \%$ of patients [4-6]. Poor efficacy can symptoms, relapse, and increased hospitalization with higher treatment costs [7-10].

A recent study exploring treatment response trajectories in schizophrenia using data from clinical trials found that $77 \%$ of patients were classified as moderate responders, $8 \%$ as poor responders, and $15 \%$ as rapid responders [11]. A study that used hospitalization as a proxy measure for psychotic symptom exacerbation over 
a 10-year period found schizophrenia amelioration in approximately $75 \%$ of patients, deterioration in approximately $25 \%$ of patients, and stability in less than $1 \%$ of patients [12]. These results underscore the need to better understand patients' heterogeneity to help improve patient long-term outcomes.

It has been suggested that the definition of "outcome" in schizophrenia may need to be broadened beyond symptom severity to also include quality of life, subjective well-being, health status, use of healthcare services, and measures of the patients' level of functioning [13-15]. Capturing multiple domains is important to assess the patient holistically and at varying stages of the illness. When outcome is broadly defined - beyond symptom improvement - relatively little is known about the baseline characteristics that can be used to predict a favorable long-term outcome among chronically ill patients with schizophrenia who are treated in usual care settings.

Using data from a large 3-year observational naturalistic noninterventional study in the United States, this analysis aimed to identify distinct health states among chronically ill patients with schizophrenia, using a broad definition of health state that incorporated severity of symptoms, level of functioning, and use of acute care services. Employing these health states, which varied from "best" to "worst," the second part of the analysis aimed to identify patients who achieved sustained favorable long-term outcome and the best baseline predictors of this favorable health state.

\section{Methods \\ Data Source}

The data source for this study was the United States (US) Schizophrenia Care and Assessment Program (SCAP), a 3-year prospective, observational study $(\mathrm{N}=$ 2327). Participants were adults 18 years and older and treated for schizophrenia, schizoaffective, or schizophreniform disorders, based on Diagnostic and Statistical Manual of Mental Disorders, fourth edition (DSM-IV) criteria. The study was conducted between July 1997 and September 2003, and the sample was geographically and ethnically diverse, representing treatment in large systems of care. Patients were recruited from community mental health centers, university healthcare systems, community and state hospitals, and the Department of Veterans Affairs Health Services [16]. The overall objective of US-SCAP was to better understand the treatment of patients with schizophrenia in usual care settings. Patients were excluded if they were unable to provide informed consent or had participated in a clinical drug trial within 30 days prior to enrollment. Enrollment was not contingent upon being treated with a specific antipsychotic or with any medication. Patients could continue with medications they received prior to enrollment for as long as necessary, and decisions about medication changes, if any, reflected those made by physicians and their patients, as they naturally occur in usual practice. Almost all study participants were outpatients at the time of enrollment (93.5\%). Of 2327 participants, most completed 1 year of follow-up (78.1\%), with fewer completing 2 years $(69.6 \%)$ and 3 years $(65.2 \%)$. At enrollment, almost all patients $(94.7 \%)$ were treated with at least one antipsychotic medication, including oral typical (36.7\%), oral atypical (58.1\%), and depot typical antipsychotics (19.6\%). Treatment throughout the study was based on physicians' decisions, which could include medication augmentation, switching, or discontinuation, reflecting the dynamic antipsychotic treatment observed in naturalistic care settings. Institutional Review Board (IRB) approval was obtained at each regional site prior to initiation of the study, and the study was conducted in accordance with the ethical principles that have their origin in the Declaration of Helsinki and are consistent with good clinical practices and applicable laws and regulations. Informed consent was received from all participants.

\section{Measures}

This study used a number of clinician-rated and patientreported measures in addition to patients' medical records. Patients' medical records provided information about healthcare utilization, such as psychiatric hospitalizations and medications (i.e., antipsychotics, antidepressants, mood stabilizers, antiparkinsonian agents, and mood stabilizers). This information was systematically collected using the Medical Records Abstraction Form (MRAF). Information about functional and quality-oflife outcomes was derived from the SCAP Health Questionnaire (SCAP-HQ) [17]. This 102-item structured interview was developed for the US-SCAP study and was administered to patients at enrollment and at 6month intervals thereafter. Items for the SCAP-HQ were drawn from existing measures, such as the Lehman Quality of Life Interview [18], the Arkansas Schizophrenia Outcomes Module $[19,20]$, the Medical Outcome Study Short Form-12 (SF-12) [21], and the CAGE, a screening tool for assessment of alcohol-related problems [22]. The psychometric properties of the SCAPHQ were found to be acceptable for application to large-scale studies in routine care based on a study of its internal consistency, convergent validity, test-retest reliability, and responsiveness to change.

Patient symptoms of schizophrenia and depressive symptoms were assessed annually by a clinician using the Positive and Negative Syndrome Scale (PANSS) [23] and the Montgomery-Åsberg Depression Rating Scale (MADRS) [24], respectively. Clinicians also annually 
assessed medication-emergent adverse events, including extrapyramidal side effects using the Simpson-Angus Scale [25] and tardive dyskinesia using the Abnormal Involuntary Movement Scale (AIMS) [26]. In addition to using the SCAP-HQ to evaluate both patient-reported level of functioning and quality of life, clinicians also used the Global Assessment of Functioning (GAF) [27] to evaluate level of functioning and the Quality of Life Scales (QLS) [28] to evaluate quality of life.

Socio-demographic information data were collected at enrollment and included age, gender, race, marital status, education, employment, and insurance status. In addition, DSM-IV diagnosis of schizophrenia (i.e., schizophrenia, schizoaffective, or schizophreniform) and age of illness onset were included. The remaining measures investigated in this analysis are described in Table 1.

The objectives of this study were: 1) to identify patients with schizophrenia who experience sustained favorable long-term outcome when the outcome incorporates severity of symptoms, level of functioning, and use of acute care services and 2) to identify the baseline measures that predict sustained favorable long-term outcome.

\section{Definition of Schizophrenia Health State and Sustained Favorable Long-Term Outcome}

The first step in this retrospective analysis was to define each patient's health state at baseline using symptom severity, level of functioning, and utilization of acute care services in a cluster analysis. Symptom severity was based on PANSS factor subscale scores [29]: PANSS positive, PANSS negative, PANSS hostility, PANSS disorganized thinking, and PANSS anxiety/depression. The level of functioning reflected patient-reported productivity (SCAP-HQ; composite measure of reported working for pay, volunteering, attending school, and keeping house or taking care of children) and clinician-rated occupational role functioning (QLS item 9) and level of accomplishment (QLS item 10). Acute care services included self-reported psychiatric hospitalization (in the previous 4 weeks) or use of emergency services (emergency room use in the previous 6 months from the medical record or self-reported emergency visit with a psychiatrist in the previous 4 weeks).

Once the health states had been defined by the cluster analysis, the next step included identifying those with sustained favorable long-term outcome, which was the main outcome of interest. A patient was classified as having sustained favorable long-term outcome if they were in the "best" cluster (i.e., experienced the lowest symptom severity and the highest level of functioning) over a 2-year period postbaseline assessment (from year 1 to year 2 and from year 2 to year 3, as assessments were conducted annually postbaseline). Change over time was ascertained by shifts in clusters from baseline to each postbaseline visit (end of year 1, 2, and 3). The last step in the retrospective analysis was to identify baseline measures that were associated with sustained favorable long-term outcome.

\section{Statistical Methods}

As mentioned above, the first step was to define each patient's health state at baseline. This was determined by a hierarchical cluster analysis, using the Ward's minimum variance method [30], of patients' schizophrenia health states to categorize patients into distinct groups at baseline. Postbaseline clusters were defined by first performing a principal component analysis on the 10 health state measures for data at baseline and each postbaseline visit. The "center" for each of the baseline clusters was defined by computing a mean score for each of the resulting 10 principal components at baseline by cluster. Then Euclidean distances were calculated from the "center" of each of the baseline clusters to each patient's 10 principal components at postbaseline. Finally, each patient's postbaseline cluster assignment was determined based on their closest Euclidean distance to each of the clusters at baseline. Patients were required to have nonmissing data for all health state measures (i.e., PANSS subscale scores, QLS items 9 and 10, psychiatric hospitalizations, and emergency services) to be included in the cluster analysis at each time point.

In addition to characterizing patients by sustained favorable long-term outcome in the second step of the analysis, cluster shifts were explored during the threeyear period. Improvement of outcome was based on changes to a better cluster from baseline to 1-year postbaseline and maintaining the same improved cluster or moving to an even better cluster the following 2 years. Worsening of outcome was based on changes to a worse cluster from baseline to 1-year postbaseline and staying in that cluster or shifting to an even worse cluster the following 2 years. Patients who did not experience improvement or worsening of outcome were classified as having "no sustained shift in outcome."

Comparisons of baseline characteristics between patients with and without sustained favorable long-term outcome were performed using Fisher's exact tests (categorical) and analysis of variance (continuous). Stepwise logistic regression, following 5 multiple imputations of missing values, was used to determine baseline factors associated with sustained favorable long-term outcome. A total of 62 variables, including the patient-reported variables, clinician-rated variables, and medical recordbased resource utilization, were explored. The interdependent variables (variance inflation factor $>10$ ) were removed. A 2-tailed significance level of 0.05 was used 
Table 1 Description of Measures

\begin{tabular}{lcr}
\hline MEASURE & SOURCE & DESCRIPTION \\
\hline SOCIO-DEMOGRAPHICS & & \\
\hline Family history & $\begin{array}{c}\text { Screening } \\
\text { interview }\end{array}$ & $\begin{array}{c}\text { History of emotional or psychiatric illness for any of the following family members: } \\
\text { parent, sibling, child, grandparent, aunt, uncle, cousin, or distant relative }\end{array}$ \\
Supervised housing & SCAP-HQ & $\begin{array}{c}\text { Includes in house/apartment where mental health professionals visit, in program with } \\
\text { mental health professionals there most of the time, in a hospital or nursing home, or in }\end{array}$
\end{tabular}
jail or prison

\section{DISEASE-RELATED AND SYMPTOMS}

Depression

MADRS total

MADRS

Remission

PANSS

PANSS anxiety/depression (Marder)*

PANSS

PANSS disorganized (Marder)*

PANSS

PANSS hostility (Marder)*

PANSS

PANSS negative (Marder)*

PANSS

PANSS positive (Marder)*

PANSS

PANSS Bell factor

PANSS

Psychosis

SCAP-HQ

Vitality

SCAP-HQ

\section{FUNCTIONING/BEHAVIORS}

Arrested

Daily Activity

SCAP-HQ

SCAP-HQ

Global assessment of functioning

Health status

SCAP-HQ

Helped by anyone

SCAP-HQ

Leisure activity

SCAP-HQ

Mental and physical health (SF-12)

SCAP-HQ

Productivity*

SCAP-HQ

Social activity

SCAP-HQ

Social relationships

SCAP-HQ

Substance abuse
Bothered much by feeling low in energy or slowed down, feeling unhappy, sad, or blue, feeling hopeless about the future, or feeling like a good or worthless person in the past 4 weeks

Combines apparent sadness, reported sadness, inner tension, reduced sleep, reduced appetite, concentration difficulties, lassitude, inability to feel, pessimistic thoughts, and suicidal thoughts

A mild, minimal, or absent response to the lack of spontaneity and flow of conversation, conceptual disorganization, delusions (general), unusual thought content, passive/apathetic social withdrawal, hallucinatory behavior, blunted affect, and stereotyped thinking items of the PANSS

Combines the disorientation, difficulty in abstract thinking, lack of judgment and insight, and hostility items of the scale

Combines the poor rapport, somatic concern, excitement, tension, mannerisms and posturing, uncooperativeness, and disturbance of volition items of the scale

Combines the anxiety, suspiciousness, emotional withdrawal, and poor attention items of the scale

Combines the passive/apathetic social withdrawal, active social avoidance, poor impulse control, hallucinatory behavior, depression, blunted affect, and preoccupation items of the scale

Combines the lack of spontaneity and flow of conversation, conceptual disorganization, delusions, unusual thought content, guilt feelings, grandiosity, stereotyped thinking, and motor retardation items of the scale

Combines the conceptual disorganization, difficult in abstract thinking, lack of judgment and insight, stereotyped thinking, and poor attention items of the scale

Bothered much by feeling that others are spying against you or plotting against you, hearing voices that other people do not hear, feeling like someone is controlling your thoughts/movements, feeling that you are watched or talked about by others, or feeling like other people are aware of your private thoughts in the past 4 weeks

Bothered much by feeling low in energy or slowed down in the past 4 weeks 
Table 1 Description of Measures (Continued)

\begin{tabular}{|c|c|c|}
\hline Suicide & SCAP-HQ & $\begin{array}{c}\text { Thought or talked about hurting or killing yourself or actually attempted to hurt or kill } \\
\text { yourself in the past } 4 \text { weeks }\end{array}$ \\
\hline Victim & SCAP-HQ & $\begin{array}{c}\text { Been a victim of a violent crime (e.g., assault, rape, mugging, or robbery) or nonviolent } \\
\text { crime (e.g., theft or being cheated) in the past } 4 \text { weeks }\end{array}$ \\
\hline Violent & SCAP-HQ & $\begin{array}{c}\text { Struck or injured someone or threatened to strike or injure someone and meant it in } \\
\text { the past } 4 \text { weeks }\end{array}$ \\
\hline Satisfaction with basic needs & SCAP-HQ & $\begin{array}{c}\text { Combines the patient's feeling about the amount of privacy where they live, the way } \\
\text { things are in general between them and their family, and the protection they have } \\
\text { against being robbed or attacked }\end{array}$ \\
\hline Satisfaction with social life & SCAP-HQ & $\begin{array}{c}\text { Combines the patient's feeling about the way they spend their time, the amount of fun } \\
\text { they have, and the amount of friendships in their life }\end{array}$ \\
\hline General life satisfaction & SCAP-HQ & $\begin{array}{l}\text { The patient's feeling about their life in general (combining satisfaction with social life } \\
\text { and basic needs) }\end{array}$ \\
\hline Quality of life scale - item $9^{*}$ & QLS & Extent of occupational role functioning \\
\hline Quality of life scale - item $10^{*}$ & QLS & Level of accomplishment \\
\hline Quality of life scale total & QLS & $\begin{array}{c}\text { Combines intimate relationship with household members, intimate relationships with } \\
\text { people other than immediate family or household members, active acquaintances, level } \\
\text { of social activity, involved social network, social initiatives, social withdrawal, socio- } \\
\text { sexual relations, extent of occupational role functioning, level of accomplishment, } \\
\text { degree of underemployment, satisfaction with occupational role functioning, sense of } \\
\text { purpose, degree of motivation, curiosity, anhedonia, time utilization, commonplace } \\
\text { objects, commonplace activities, capacity for empathy, and capacity for engagement } \\
\text { and interaction with interviewer }\end{array}$ \\
\hline
\end{tabular}

\section{HEALTHCARE RESOURCE UTILIZATION}

\begin{tabular}{|c|c|c|}
\hline Case management & MRAF & Case management (documented in medical record within the past 6 months) \\
\hline Crisis call & SCAP-HQ & Called a crisis hotline in the past 4 weeks \\
\hline Emergency service use* & $\begin{array}{l}\text { SCAP-HQ } \\
\text { MRAF }\end{array}$ & $\begin{array}{l}\text { Had an unscheduled emergency visit with a psychiatrist or therapist in the past } 4 \\
\text { weeks } \\
\qquad \begin{array}{l}\text { Emergency room visit (past } 6 \text { months) }\end{array}\end{array}$ \\
\hline Individual therapy & MRAF & Received individual therapy (past 6 months) \\
\hline $\begin{array}{l}\text { Number of hospitalizations/total number of } \\
\text { days hospitalized ( } 6 \text { months) }\end{array}$ & MRAF & Used admission and discharge dates reported on the medical record extraction form \\
\hline Psychiatric hospitalizations (4 weeks)* & SCAP-HQ & Stayed overnight in a hospital for a mental or emotional problem \\
\hline Psychiatric hospitalizations (1 year) & $\begin{array}{l}\text { Screening } \\
\text { interview }\end{array}$ & Been in the hospital for a mental or emotional problem in the last year \\
\hline \multicolumn{3}{|l|}{ MEDICATION ADHERENCE } \\
\hline Medication possession ratio & MRAF & $\begin{array}{l}\text { The cumulative number of days the patient had been prescribed any antipsychotic } \\
\text { drug divided by the number of days in the assessment period multiplied by } 100\end{array}$ \\
\hline Non-adherence & $\mathrm{SCAP}-\mathrm{HQ}$ & $\begin{array}{l}\text { How regularly did the patient take the medication they were given for mental, } \\
\text { emotional, or nervous problems in the past } 4 \text { weeks }\end{array}$ \\
\hline
\end{tabular}

\section{MEDICATION-EMERGENT EVENTS}

Level of abnormal involuntary movements

Clearer thoughts from medication

Medication effects

Tardive dyskinesia

Psuedo-parkinsonian symptoms

SA

Restlessness

SCAP-HQ
Combines facial and oral movements (muscles of facial expression, lips and perioral area, jaw, tongue), extremity movements (upper [arms, wrists, hands, fingers], lower [legs, knees, ankles, toes]), and trunk movements (neck, shoulders, hips)

SCAP-HQ Current medication for mental, emotional, or nervous problem is making your thoughts clearer

SCAP-HQ Current medication for mental, emotional, or nervous problem is making your thoughts clearer, making you feel tired and sluggish, interfering with your normal thinking, making you feel restless, or interfering with your normal sexual functioning

A response of moderate or severe on either facial and oral movements (muscles of facial expression, lips and perioral area, jaw, tongue), extremity movements (upper [arms, wrists, hands, fingers], lower [legs, knees, ankles, toes]), or trunk movements (neck, shoulders, hips) or a response of mild, moderate, or severe on any 2 of the previous items

Combines gait, arm dropping, shoulder shaking, elbow rigidity, fixation of position or wrist rigidity, leg pendulousness, glabella tap, tremor, and salivation

Medication for mental, emotional, or nervous problem is making you feel restless

Abbreviations: AIMS = abnormal involuntary movement scale, BDCF = baseline demographic collection form, GAF = global assessment form, MADRS =

Montgomery-Åsberg depression rating scale, MRAF = medical record assessment form, PANSS = positive and negative syndrome scale, QLS = quality of life scale,

$\mathrm{SA}=$ Simpson-Angus scale, SCAP-HQ = schizophrenia care and assessment program-health questionnaire; SF = short form.

* Measures used in the schizophrenia health state definition.

NOTE: The various patient-reported and clinician reported measures in addition to the items obtained from the medical records investigated in this analysis. 
to determine whether a baseline measure was included in or excluded from the model.

\section{Results}

Most (83\% or $1942 / 2327)$ study enrollees had sufficient baseline data for inclusion in the cluster analysis. A baseline comparison of the patients included in the cluster analysis and those not included revealed that the included patients were significantly older (42.2 years versus 40.3 years; $p=.0029)$ and less likely to be unemployed $(77.6 \%$ versus $83.4 \% ; \mathrm{p}=.0122)$ and had lower PANSS positive scores (17.9 versus $19.5 ; \mathrm{p}<.0001)$, lower PANSS negative scores (17.8 versus $19.1 ; \mathrm{p}=$ .0002), lower PANSS hostility scores (10.4 versus 11.3; p $<.0001)$, lower PANSS anxiety/depression scores (10.4 versus 11.2; $\mathrm{p}<.0001)$, and higher GAF scores $(43.7$ versus $33.7 ; \mathrm{p}<.0001)$.

There were 5 distinct health state clusters identified (Table 2) in the first step of the analysis and labeled from the "best" to "worst" cluster, with severity of symptoms and level of functioning influencing cluster order. The majority of patients (77\%) belonged to either the "best" $(\mathrm{n}=503)$ or the "second best" $(\mathrm{n}=992)$ clusters at baseline. Although the average symptom severity and level of functioning was worse for patients in the "worst" cluster, all of the acute care services were experienced by patients in the "middle" and "second worst" groups.

Approximately $70 \%$ of the patients had postbaseline data to examine sustained favorable long-term outcome for the second step of the analysis. A baseline comparison of these patients $(n=1635)$ and those not included $(\mathrm{n}=692)$ revealed that the included patients were older (42.3 years versus 40.8 years; $\mathrm{p}=.0039$ ), had higher PANSS positive scores $(18.5$ versus $17.3 ; \mathrm{p}<.0001)$, higher PANSS negative scores (18.3 versus 17.3 ; $\mathrm{p}=$ .0007), higher PANSS disorganized scores (13.7 versus $12.8 ; \mathrm{p}<.0001)$, higher PANSS hostility scores $(10.8$

Table 2 Baseline Characteristics for Variables Used to Define Health States by Cluster $(n=1942)$

\begin{tabular}{|c|c|c|c|c|c|c|}
\hline Cluster Variables & $\begin{array}{c}\text { Best } \\
\mathrm{n}=503\end{array}$ & $\begin{array}{c}\text { Second Best } \\
n=992\end{array}$ & $\begin{array}{l}\text { Middle } \\
\mathrm{n}=145\end{array}$ & $\begin{array}{l}\text { Second Worst } \\
n=53\end{array}$ & $\begin{array}{c}\text { Worst } \\
n=249\end{array}$ & $\begin{array}{c}\text { Total } \\
(\mathrm{n}=1942)\end{array}$ \\
\hline \multicolumn{7}{|l|}{ SYMPTOM SEVERITYa } \\
\hline $\begin{array}{l}\text { PANSS positive, } \\
\text { mean (sd) }\end{array}$ & $13.81(3.92)$ & $18.02(5.38)$ & $19.24(6.70)$ & $19.72(6.32)$ & $24.34(5.27)$ & $17.88(6.05)$ \\
\hline $\begin{array}{l}\text { PANSS negative, } \\
\text { mean (sd) }\end{array}$ & $13.17(4.06)$ & $17.98(5.33)$ & $20.08(6.48)$ & $20.17(5.99)$ & $24.54(5.77)$ & $17.79(6.25)$ \\
\hline $\begin{array}{l}\text { PANSS hostility, } \\
\text { mean (sd) }\end{array}$ & $7.77(2.43)$ & $10.57(3.35)$ & $11.53(3.86)$ & $12.08(3.10)$ & $14.32(2.79)$ & $10.44(3.68)$ \\
\hline $\begin{array}{l}\text { PANSS disorganized thinking, } \\
\text { mean (sd) }\end{array}$ & $10.66(2.67)$ & $12.99(3.64)$ & $13.89(4.65)$ & $14.43(3.80)$ & $19.75(3.97)$ & $13.36(4.46)$ \\
\hline PANSS anxiety/depression & $8.61(2.88)$ & $10.51(3.06)$ & $9.91(3.16)$ & $10.76(3.36)$ & $13.61(3.10)$ & $10.38(3.37)$ \\
\hline \multicolumn{7}{|l|}{ FUNCTIONING } \\
\hline Occupational role functioning (QLS 9), mean (sd) & $3.59(1.55)$ & $1.66(1.62)$ & $1.65(1.73)$ & $1.34(1.34)$ & $0.46(0.80)$ & $1.99(1.83)$ \\
\hline Level of accomplishment (QLS 10), mean (sd) & $4.39(1.08)$ & $2.07(1.54)$ & $2.10(1.84)$ & $1.58(1.41)$ & $0.68(0.91)$ & $2.48(1.84)$ \\
\hline Productivity, n (\%) & $503(100 \%)$ & $605(61)$ & $90(62.1)$ & $38(71.7)$ & $92(36.9)$ & $1328(68.4)$ \\
\hline \multicolumn{7}{|l|}{ ACUTE CARE } \\
\hline Emergency use ${ }^{\mathrm{b}}, \mathrm{n}(\%)$ & 0 & 0 & $145(100)$ & $18(34)$ & 0 & $163(8.4)$ \\
\hline $\begin{array}{l}\text { Psychiatric hospitalizations, } \\
\text { (past } 4 \text { weeks), n (\%) }\end{array}$ & 0 & 0 & 0 & $53(100)$ & 0 & $53(2.7)$ \\
\hline
\end{tabular}

Abbreviations: $\mathrm{n}=$ number of patients; PANSS = positive and negative syndrome scale; QLS = Quality of Life Scale; sd = standard deviation.

a PANSS factors per Marder et al. (1997) [29]

${ }^{\mathrm{b}}$ Emergency use was both patient reported for the past 4 weeks and from the past 6 months recorded in the medical record.

NOTE: There were 5 distinct outcome clusters identified and labeled from the "best" to "worst" cluster, with severity of symptoms and level of functioning influencing cluster order. The majority of patients $(77 \%)$ belonged to either the "best" $(n=503)$ or the "second best" ( $n=992)$ clusters at baseline. 
versus 10.2; $\mathrm{p}=.0004)$, lower GAF scores (41.6 versus 43.3; $\mathrm{p}=.0063)$, and lower mean QLS total scores $(2.8$ versus $3.0 ; \mathrm{p}=.0216)$. Of the 1635 patients included in the analysis, 369 (23\%) were closest to the "best" cluster at year 1; 209 (13\%) achieved favorable outcome over 1 year (from year 1 to year 2); and 157 (10\%) achieved favorable sustained outcome over 2 years (from year 1 to year 3) (Figure 1).

An assessment of cluster shift over time was conducted to further understand change over the 3-year period, and patients were classified as "improved," "worsened," or "no sustained shift of health state." Most patients ( $85 \% ; n=688)$ showed "no sustained shift," while $10 \%(\mathrm{n}=84)$ showed "improved" health state and only $4 \%(\mathrm{n}=34)$ had "worsened" over the length of the study.

The comparison of baseline characteristics for patients with and without sustained favorable long-term outcome over the 2-year postbaseline period are shown in Table 3 . In general, the univariate analyses showed that patients with sustained favorable long-term outcome started out better compared with those without sustained favorable long-term outcome. At baseline, they were significantly more likely to have fewer symptoms, higher level of functioning, better quality of life, satisfaction with life, fewer medication-emergent events, and lower healthcare resource utilization.

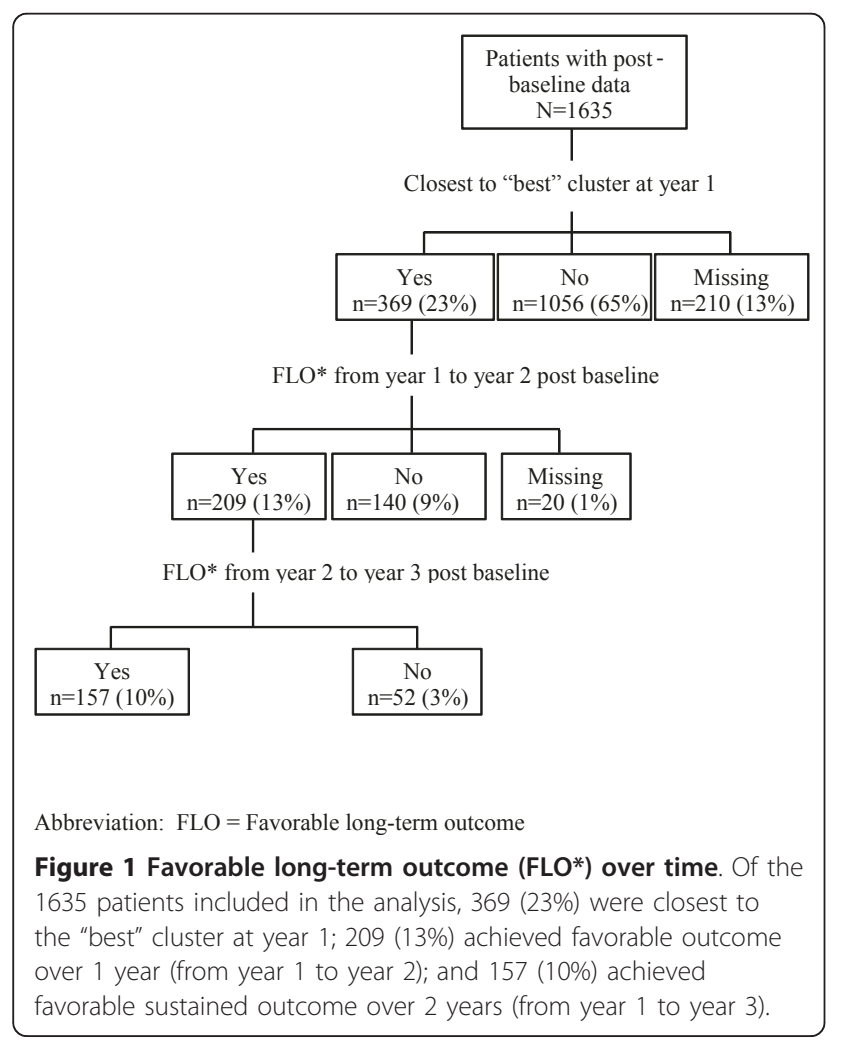

When assessing the association (OR [95\% CI]) between all baseline measures and sustained favorable long-term outcome in the last step of the analysis, only 9 variables remained statistically significant (Figure 2). Patients who were employed (1.98 [1.34, 2.91]), shopped without receiving assistance (1.76 [1.19, $2.59]$ ), and engaged in leisure activities without receiving assistance $(1.75[1.10,2.79])$ had significantly greater odds of experiencing sustained favorable longterm outcome, while those who received individual therapy $(0.47[0.25,0.88])$ and were victims of a violent or non-violent crime $(0.38[0.17,0.85])$ had significantly lower odds of experiencing sustained favorable longterm outcome. In addition, patients experiencing clearer thoughts from their medication (1.21 [1.04, 1.40]), a better quality of life (mean QLS total score: 1.64 [1.32, 2.03]), better global functioning (1.04 [1.02, $1.06])$, and more daily activities $(1.27[1.06,1.52])$ had significantly greater odds of experiencing sustained favorable long-term outcome.

\section{Discussion}

Using data from a large 3-year prospective observational study, this analysis identified 5 distinct health state clusters among chronically ill patients with schizophrenia treated in usual care settings in the US. This analysis incorporated its definition of patients' health state, severity of symptoms level of functioning, and use of acute care services, thus reflecting a broader health state concept that is not confined to symptomatology alone. Although the concept of broadening the definition of outcome has been utilized in a few prior schizophrenia studies, these studies have incorporated only patient's level of functioning along with symptoms [13-15]. To our knowledge, incorporating the patient's use of acute care services, severity of symptoms, and level of function has not been previously explored in the literature and provides a holistic view of the health status of the patient.

In this study, only $10 \%$ of the patients achieved "sustained favorable long-term outcome" over a 2-year period. A further assessment of cluster shift over the 3-year study period showed that a few patients (10\%) improved over time (based on the definition of sustained favorable outcome), while the majority of patients (85\%) had no sustained change from baseline in health state. Current findings suggest there continues to be a great need for improvement in the health status, and thus the need for better treatments, of these chronically ill patients with schizophrenia. This is a consistent message from past research, although this current study shows that a rather small percentage of patients are achieving "sustained long-term favorable outcome." Past research, which used a different definition of outcome and a different study 
Table 3 Baseline Characteristics by Sustained Favorable Long-Term Outcome $(\mathbf{N}=1635)$

\begin{tabular}{|c|c|c|c|}
\hline & \multicolumn{3}{|c|}{ SUSTAINED FAVORABLE LONG-TERM OUTCOME } \\
\hline & $\begin{array}{c}\text { Yes } \\
\mathrm{n}=157\end{array}$ & $\begin{array}{c}\text { No } \\
n=1478\end{array}$ & $\begin{array}{c}\text { Univariate } \\
\mathrm{p} \text { value }\end{array}$ \\
\hline \multicolumn{4}{|l|}{ SOCIO-DEMOGRAPHICS } \\
\hline Age, mean (sd) & $42.09(10.61)$ & $42.31(11.00)$ & .8182 \\
\hline Male, n (\%) & $77(49.0)$ & $924(62.5)$ & .0010 \\
\hline \multicolumn{4}{|l|}{ Race/ethnicity, n (\%) } \\
\hline Caucasian & $86(54.8)$ & $800(54.1)$ & .7398 \\
\hline African-American & $61(38.9)$ & $538(37.8)$ & \\
\hline Other & $10(6.4)$ & $120(8.1)$ & \\
\hline Single marital status, $\mathrm{n}(\%)$ & $142(91.0)$ & $1324(90.2)$ & .7380 \\
\hline High school education or less, $\mathrm{n}(\%)$ & $43(27.6)$ & $508(34.6)$ & .0774 \\
\hline Employed, n (\%) & $66(42.0)$ & $271(18.4)$ & $<.0001$ \\
\hline Lack of health insurance, $\mathrm{n}(\%)$ & $20(12.7)$ & $78(5.3)$ & .0002 \\
\hline Family history, $\mathrm{n}(\%)$ & $80(55.2)$ & $776(56.7)$ & .7198 \\
\hline Supervised housing, n (\%) & $24(15.3)$ & $483(33.2)$ & $<.0001$ \\
\hline \multicolumn{4}{|l|}{ DISEASE-RELATED AND SYMPTOMS } \\
\hline Age at illness onset, mean (sd) & $21.50(9.33)$ & $19.97(8.70)$ & .0446 \\
\hline Depression, mean (sd) & $2.01(0.88)$ & $2.41(1.01)$ & $<.0001$ \\
\hline MADRS total score, mean (sd) & $9.89(8.79)$ & $14.68(10.26)$ & $<.0001$ \\
\hline PANSS positive (symptom $\left.{ }^{a}\right)$, mean (sd) & $14.89(5.10)$ & $18.84(6.08)$ & $<.0001$ \\
\hline PANSS negative (symptom ${ }^{a}$ ), mean (sd) & $14.10(5.00)$ & $18.72(6.18)$ & $<.0001$ \\
\hline PANSS hostility (symptomª), mean (sd) & $8.52(3.40)$ & $10.99(3.63)$ & $<.0001$ \\
\hline PANSS disorganized (symptomª), mean (sd) & $11.36(3.51)$ & $13.92(4.52)$ & $<.0001$ \\
\hline PANSS anxiety/depression (symptom $\left.{ }^{a}\right)$, mean (sd) & $9.02(2.93)$ & $10.71(3.41)$ & $<.0001$ \\
\hline Remission (PANSS), n (\%) & $66(43.1)$ & $293(20.0)$ & $<.0001$ \\
\hline PANSS total score, mean (sd) & $57.79(15.54)$ & $72.58(18.22)$ & $<.0001$ \\
\hline PANSS Bell factor, mean (sd) & $11.22(4.32)$ & $13.78(5.01)$ & $<.0001$ \\
\hline Psychosis, mean (sd) & $1.63(0.84)$ & $2.01(1.05)$ & $<.0001$ \\
\hline Vitality, mean (sd) & $3.55(1.17)$ & $3.19(1.29)$ & .0008 \\
\hline \multicolumn{4}{|l|}{ FUNCTIONING/BEHAVIORS } \\
\hline Daily activities, mean (sd) & $3.95(0.95)$ & $3.30(1.21)$ & $<.0001$ \\
\hline Leisure activities, mean (sd) & $3.18(0.97)$ & $2.64(1.19)$ & $<.0001$ \\
\hline Social activities, mean (sd) & $2.96(0.98)$ & $2.62(1.06)$ & .0001 \\
\hline Social relationships, mean (sd) & $3.17(1.10)$ & $2.82(1.23)$ & .0005 \\
\hline Arrested $^{c}, \mathrm{n}(\%)$ & $4(2.5)$ & $79(5.4)$ & .1268 \\
\hline \multicolumn{4}{|l|}{ Violence, n (\%) } \\
\hline No thought of injuring anyone & $152(96.8)$ & $1372(93.1)$ & .0358 \\
\hline Thoughts of injuring someone & 0 & $60(4.1)$ & \\
\hline Have injured someone & $5(3.2)$ & $42(2.8)$ & \\
\hline Victim of a crime, n (\%) & $8(5.1)$ & $166(11.3)$ & .0170 \\
\hline Suicide thought/attempt, n (\%) & $18(11.5)$ & $249(16.9)$ & .0789 \\
\hline Substance use, n (\%) & $44(28.0)$ & $386(26.2)$ & .6262 \\
\hline Received helped with shopping, n (\%) & $59(37.6)$ & $840(57.1)$ & $<.0001$ \\
\hline Received helped with leisure, n (\%) & $28(17.8)$ & $478(32.5)$ & .0002 \\
\hline Received helped with household chores, n (\%) & $70(44.6)$ & $790(53.6)$ & .0309 \\
\hline Received helped with paying bills, n (\%) & $77(49.0)$ & $899(61.1)$ & .0035 \\
\hline Received helped with job search, n (\%) & $29(18.5)$ & $246(16.8)$ & .5940 \\
\hline Received helped with getting benefits, n (\%) & $39(25.2)$ & $472(32.1)$ & .0782 \\
\hline Received helped with legal issues, n (\%) & $11(7.1)$ & $142(9.7)$ & .3046 \\
\hline General life satisfaction, mean (sd) & $5.02(1.47)$ & $4.53(1.59)$ & .0002 \\
\hline Satisfaction with basic needs, mean (sd) & $5.23(1.04)$ & $4.71(1.12)$ & $<.0001$ \\
\hline
\end{tabular}


Table 3 Baseline Characteristics by Sustained Favorable Long-Term Outcome ( $\mathbf{N}=1635)$ (Continued)

\begin{tabular}{|c|c|c|c|}
\hline Satisfaction with social life, mean (sd) & $5.08(0.85)$ & $4.57(1.05)$ & $<.0001$ \\
\hline SF 12-Mental Health, mean (sd) & $45.22(12.44)$ & $40.45(13.34)$ & $<.0001$ \\
\hline SF 12-Physical Health, mean (sd) & $47.70(11.29)$ & $45.17(12.99)$ & .0192 \\
\hline Occupational role functioning (QLS 9), mean (sd) & $3.15(1.88)$ & $1.76(1.73)$ & $<.0001$ \\
\hline Level of accomplishment (QLS 10), mean (sd) & $3.86(1.61)$ & $2.23(1.77)$ & $<.0001$ \\
\hline Mean QLS total, mean (sd) & $3.71(1.06)$ & $2.74(1.01)$ & $<.0001$ \\
\hline Global Assessment of Functioning (GAF), mean (sd) & $52.59(13.74)$ & $40.48(12.09)$ & $<.0001$ \\
\hline $\begin{array}{l}\text { Overall impression of general health } \\
\text { (good/very good/excellent), } n(\%)\end{array}$ & $116(73.9)$ & $885(60.2)$ & .0008 \\
\hline Productivity, n (\%) & $138(87.9)$ & $916(62.1)$ & $<.0001$ \\
\hline \multicolumn{4}{|l|}{ MEDICATION ADHERENCE } \\
\hline Medication possession ratio < .80, $\mathrm{n}(\%)$ & $21(13.9)$ & $140(9.9)$ & .1274 \\
\hline Non-adherence, n (\%) & $6(3.9)$ & $110(7.6)$ & .0909 \\
\hline \multicolumn{4}{|l|}{ MEDICATION-EMERGENT EVENTS } \\
\hline AIMS total, mean (sd) & $2.28(3.16)$ & $3.52(4.20)$ & .0005 \\
\hline Simpson-Angus total ${ }^{\mathrm{d}}$, mean (sd) & $2.93(3.41)$ & $4.61(4.20)$ & $<.0001$ \\
\hline Patient-reported clearer thoughts from medication, mean (sd) & $3.74(1.19)$ & $3.22(1.35)$ & $<.0001$ \\
\hline Medication effects, mean (sd) & $1.83(0.63)$ & $2.07(0.75)$ & .0001 \\
\hline Restlessness, mean (sd) & $1.68(1.13)$ & $1.87(1.17)$ & .0533 \\
\hline Tardive dyskinesia, n (\%) & $33(22.1)$ & $489(34.3)$ & .0027 \\
\hline \multicolumn{4}{|l|}{ CONCOMITANT MEDICATION } \\
\hline Mood stabilizers, n (\%) & $35(22.7)$ & $469(32.3)$ & .0145 \\
\hline Antidepressants, n (\%) & $58(37.7)$ & $573(39.5)$ & .6541 \\
\hline Antiparkinsonians, n (\%) & $64(41.6)$ & $672(46.3)$ & .2571 \\
\hline Anti-anxiety medications, n (\%) & $12(7.8)$ & $171(11.8)$ & .1376 \\
\hline \multicolumn{4}{|l|}{ HEALTHCARE RESOURCE UTILIZATION } \\
\hline Emergency service use ${ }^{\mathrm{b}}$ (acute care service), $\mathrm{n}(\%)$ & $11(7.0)$ & $174(11.8)$ & .0711 \\
\hline Psychiatric hospitalization (acute care service) (past 4 weeks), n (\%) & $7(4.5)$ & $134(9.1)$ & .0494 \\
\hline Number of hospitalizations ( 6 months), mean (sd) & $0.13(0.36)$ & $0.31(0.66)$ & .0010 \\
\hline Total number of days hospitalized (6 months), mean (sd) & $2.29(13.84)$ & $5.82(21.58)$ & .0453 \\
\hline Psychiatric hospitalizations (1-year), n (\%) & $34(21.8)$ & $509(34.8)$ & .0011 \\
\hline Crisis call & $2(1.3)$ & $73(5.0)$ & .0362 \\
\hline Case Management ${ }^{\mathrm{d}}, \mathrm{n}(\%)$ & $5(50.0)$ & $190(68.6)$ & .2158 \\
\hline Individual therapy, n (\%) & $139(89.1)$ & $1378(94.1)$ & .0145 \\
\hline
\end{tabular}

Abbreviations: AIMS = Abnormal Involuntary Movement Scale; MADRS = Montgomery-Åsberg Depression Rating Scale; $\mathrm{n}=$ number of patients; PANSS = positive and negative syndrome scale; QLS = Quality of Life Scale; sd = standard deviation; SF = short form.

a PANSS factors per Marder et al. (1997) [29]

${ }^{\mathrm{b}}$ Emergency use was both patient reported for the past 4 weeks and from the past 6 months recorded in the medical record.

c The variation inflation factor for the arrested measure was greater than 10 and therefore not included in the stepwise logistic regression model.

${ }^{\mathrm{d}}$ Measure was not included in the stepwise logistic regression due to missing data.

NOTE: The univariate comparison of baseline characteristics for patients with and without sustained favorable long-term outcome over the 2-year postbaseline period.

duration, has have shown that current medications are effective for only approximately $50 \%$ of patients [4-6].

Our findings may reflect a somewhat conservative definition of "favorable and sustained long-term outcome," considering we required patients to be closest to the best baseline health status cluster in each of the 2 years following the initial cluster assignment baseline assessment. Therefore, there is the possibility that more than $10 \%$ of patients have improved, just not to the degree defined in this study as "sustained favorable long-term outcome."

Importantly, this study identified a small set of baseline characteristics that predict long-term sustained favorable health states over the study period. These characteristics included better quality of life, more daily activities, patient-reported clearer thinking from medication, better global functioning, being employed, not receiving individual therapy, not being a victim of a 


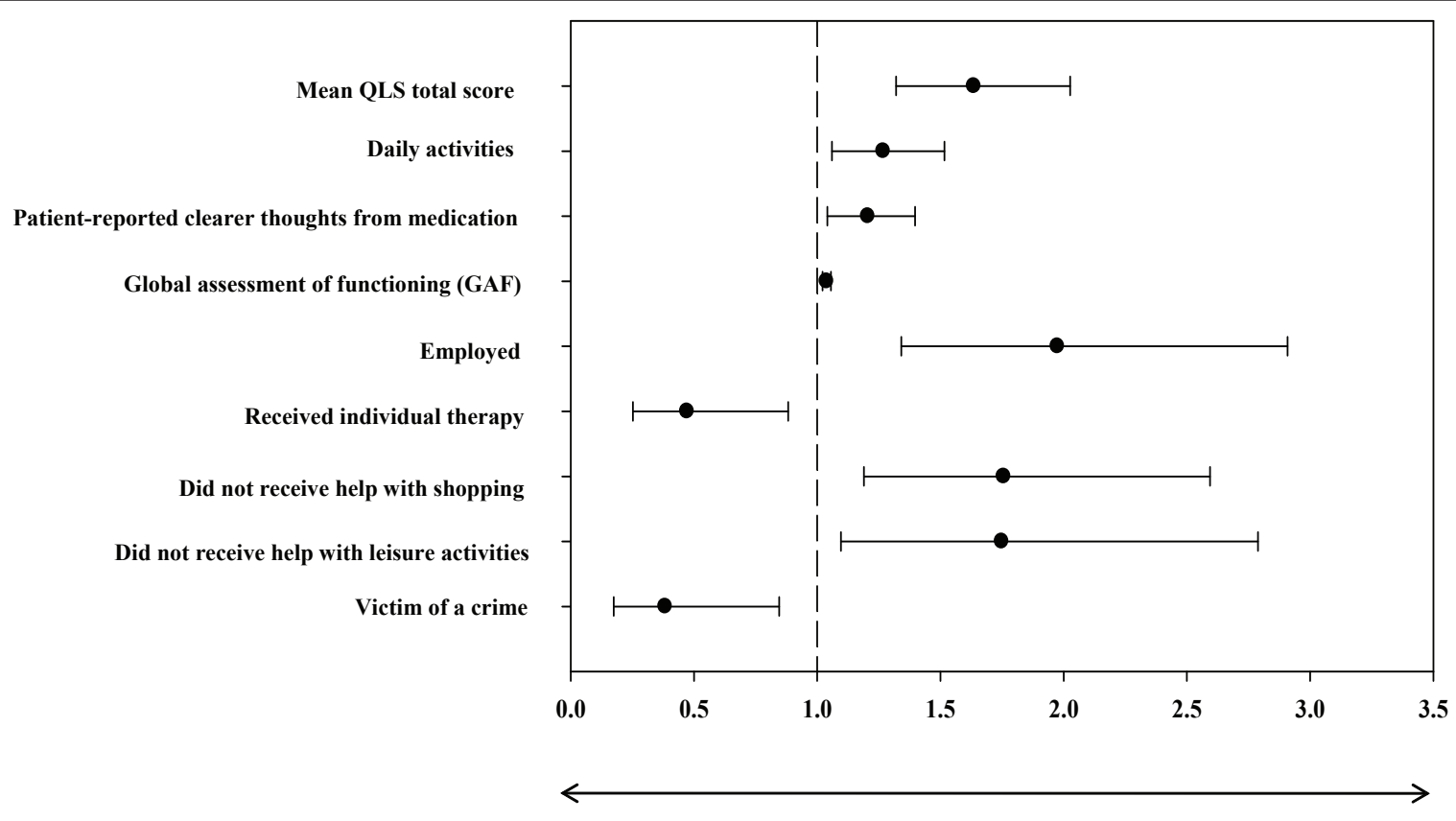

Lesser Odds

Greater Odds

Odds Ratios (95\% CI)

Abbreviation: QLS = Quality of Life Scale.

Figure 2 The best baseline predictors of sustained favorable long-term outcome over a 3-year period. When assessing the association between all baseline measures and sustained favorable long-term outcome, only 9 variables remained statistically significant.

crime, and receiving less help with shopping or leisure activities. In general, when exploring baseline factors that were associated with sustained favorable long-term outcome, patients with a less severe illness profile (i.e., quality of life and functioning) were more likely to subsequently experience the favorable outcome of interest. Results of this study are consistent with prior research using data from patients in clinical trial settings, which found that patients with a less severe illness profile at baseline (e.g., higher level of functioning) had more favorable outcomes $[14,31]$. A naturalistic study [15] also confirmed that characteristics of those patients who were functioning better at baseline was predictive of functional remission.

Of particular interest, the results indicate that more daily activities and receiving less help with shopping or leisure activities were associated with sustained favorable long-term outcome. These factors are potentially modifiable and easy to assess, thus enabling clinicians to better understand and help optimize the treatment plan for the patient.

Although prior studies utilized varying endpoints, methods, and research designs, results appear similar to the present study in that patients who had better baseline profiles appeared to have better outcomes. The present study expands on past research by exploring potential predictors of sustained favorable long-term outcome and by using a broadly defined outcome measure that combines symptom severity, level of functioning, and use of acute care sevices. Moreoever, since data from randomized controlled trials provide efficacy data in a relatively homogenous population under artifical circumstances, it is reassuring to find that these results are confirmed in usual practice real-world settings. The identification of predictors of favorable outcomes suggests that clinicians could make early projections of health states and identify those patients more likely to achieve favorable long-term outcomes, enabling early therapeutic interventions to enhance benefits for patients.

This study has a number of limitations, including infrequent assessments. Clinician-reported outcomes were obtained only annually, and patient-reported outcomes were assessed every 6 months. Due to the infrequent assessments and the fact that schizophrenia is an illness characterized by relapses and remissions, this 
study was unable to capture episodic exacerbations or relapses that may have occured between assessments. Because of these infrequent assessments, other changes within those time periods and the potentially important variable of patients' early response to therapy were not captured. Lack of early response (week 2) has been found to be an important predictor $[2,3]$ of subsequent response to therapy. There may be additional predictors not assessed, thus not explored, such as premorbid functioning, that may play an important role in patients' long-term outcomes. Also, p-values presented in the univariate analysis results were not adjusted for multiple comparisons. This study was intended for hypothesis generating as opposed to confirmation of a hypothesis, so the results would need to be replicated in a different study. Further, due to the statistical modeling of a large number of potential predictors and the method used for that analysis, we employed multiple imputation methods for missing data to reduce the number of observations deleted from the analysis. While the analysis included most $(83 \%)$ of the enrolled patients, the patients who were included in the baseline cluster analysis were found to have a milder illness profile compared with those who were excluded, and the likely impact on the current results is unknown.

\section{Conclusions}

This naturalistic, observational, 3-year study of chronically ill patients with schizophrenia identified 5 distinct health state clusters, which incorporate patients' baseline symptom severity, level of functioning, and use of acute care services. Using these health states, this study identified a small set of baseline characteristics that best predict sustained favorable long-term outcome over a 2-year postbaseline period. Findings may help clinicians tailor treatment alternatives that best meet individual patients' long-term needs. Understanding what factors may predict better long-term outcomes may also direct additional therapeutic options, enabling a holistic approach to treating patients and optimizing the potential benefit. Additional research building upon the current findings may allow for identification of early therapeutic interventions that could enhance patients' likelihood of achieving sustained favorable long-term outcomes.

\footnotetext{
Acknowledgements

This work was sponsored by Eli Lilly and Company and/or its subsidiaries. We thank Carlos I. Alatorre, PhD for his critical review of the manuscript and Kory Schuh, PhD for providing medical writing services. Drs. Alatorre and Schuh are full-time employees and minor shareholders of Eli Lilly and Company.

Authors' contributions

GBCC, DRM, HA-S, and DEF contributed to the design of the study. DRM performed the statistical analyses. GBCC, DRM, HA-S, and DEF helped to draft the manuscript and approved the final version.
}

\section{Competing interests}

The authors, Drs. Cuyún Carter, Faries, and Ascher-Svanum and Ms. Milton, are full-time employees and minor stockholders of Eli Lilly and Company and/or its subsidiaries.

Received: 28 March 2011 Accepted: 26 August 2011

Published: 26 August 2011

\section{References}

1. Stroup TS: Heterogeneity of treatment effects in schizophrenia. Am J Med 2007, 120(Suppl 1):S26-S31.

2. Kinon BJ, Chen L, Ascher-Svanum H, Stauffer VL, Kollack-Walker S, Sniadecki JL, Kane JM: Predicting response to atypical antipsychotics based on early response in the treatment of schizophrenia. Schizophr Res 2008, 102:230-240.

3. Ascher-Svanum H, Nyhuis AW, Faries DE, Kinon BJ, Baker RW, Shekhar A: Clinical, functional, and economic ramifications of early nonresponse to antipsychotics in the naturalistic treatment of schizophrenia. Schizophr Bull 2008, 34:1163-1171.

4. Kerwin RW, Osborne S: Antipsychotic drugs. Medicine 2000, 28:23-25.

5. Lieberman JA, Stroup TS, McEvoy JP, Swartz MS, Rosenheck RA, Perkins DO, Keefe RS, Davis SM, Davis CE, Lebowitz BD, Severe J, Hsiao JK, Clinical Antipsychotic Trials of Intervention Effectiveness (CATIE) Investigators: Effectiveness of antipsychotic drugs in patients with chronic schizophrenia. N Engl J Med 2005, 353:1209-1223.

6. Miyamoto S, Duncan GE, Marx CE, Lieberman JA: Treatments for schizophrenia: a critical review of pharmacology and mechanisms of action of antipsychotic drugs. Mol Psychiatry 2005, 10:79-104.

7. Ayuso-Gutiérrez JL, del Río Vega JM: Factors influencing relapse in the long-term course of schizophrenia. Schizophr Res 1997, 28:199-206.

8. Perkins DO: Predictors of noncompliance in patients with schizophrenia. J Clin Psychiatry 2002, 63:1121-1128.

9. Thieda P, Beard S, Richter A, Kane J: An economic review of compliance with medication therapy in the treatment of schizophrenia. Psychiatr Serv 2003, 54:508-516.

10. Liu-Seifert H, Adams DH, Kinon BJ: Discontinuation of treatment of schizophrenic patients is driven by poor symptom response: a pooled post-hoc analysis of four atypical antipsychotic drugs. BMC Med 2005, 3:21.

11. Levine SZ, Leucht S: Elaboration on the early-onset hypothesis of antipsychotic drug action: treatment response trajectories. Biol Psychiatry 2010, 68:86-92.

12. Rabinowitz J, Levine SZ, Haim R, Häfner H: The course of schizophrenia: progressive deterioration, amelioration or both? Schizophr Res 2007, 91:254-258.

13. Lambert M, Schimmelmann BG, Naber D, Schacht A, Karow A, Wagner T, Czekalla J: Prediction of remission as a combination of symptomatic and functional remission and adequate subjective well-being in 2960 patients with schizophrenia. J Clin Psychiatry 2006, 67:1690-1697.

14. Lipkovich IA, Deberdt W, Csernansky JG, Buckley P, Peuskens J, KollackWalker S, Rotelli M, Houston JP: Defining "good" and "poor" outcomes in patients with schizophrenia or schizoaffective disorder: a multidimensional data-driven approach. Psychiatry Res 2009, 170:161-167.

15. Schennach-Wolff $R$, Jäger $M$, Seemüller $F$, Obermeier $M$, Messer $T$, Laux $G$, Pfeiffer H, Naber D, Schmidt LG, Gaebel W, Huff W, Heuser I, Maier W, Lemke MR, Rüther E, Buchkremer G, Gastpar M, Möller HJ, Riedel M: Defining and predicting functional outcome in schizophrenia and schizophrenia spectrum disorders. Schizophr Res 2009, 113:210-217.

16. Ascher-Svanum H, Faries DE, Zhu B, Ernst FR, Swartz MS, Swanson JW: Medication adherence and long-term functional outcomes in the treatment of schizophrenia in usual care. J Clin Psychiatry 2006, 67:453-460.

17. Lehman AF, Fischer EP, Postrado L, Delahanty J, Johnstone BM, Russo PA, Crown WH: The Schizophrenia Care and Assessment Program Health Questionnaire (SCAP-HQ): an instrument to assess outcomes of schizophrenia care. Schizophr Bull 2003, 29:247-256.

18. Lehman AF: A quality of life interview for the chronically mentally ill. Evaluation and Program Planning 1988, 11:51-62.

19. Fischer EP: Mental health outcome module development and testing: development and initial validation of the schizophrenia outcomes 
module - final report, SDR Grant \#91,005. Washington, DC: Department of Veterans Affairs; 1993.

20. Cuffel BJ, Fischer EP, Owen RR Jr, Smith GR Jr: An instrument for measurement of outcomes of care for schizophrenia. Issues in development and implementation. Eval Health Prof 1997, 20:96-108.

21. Ware J Jr, Kosinski M, Keller SD: A 12-Item Short-Form Health Survey: construction of scales and preliminary tests of reliability and validity. Med Care 1996, 34:220-233

22. Mayfield D, McLeod G, Hall P: The CAGE questionnaire: validation of a new alcoholism screening instrument. Am J Psychiatry 1974, 131:1121-1123.

23. Kay SR, Fiszbein A, Opler LA: The positive and negative syndrome scale (PANSS) for schizophrenia. Schizophr Bull 1987, 13:261-276.

24. Montgomery SA, Åsberg M: A new depression scale designed to be sensitive to change. Br J Psychiatry 1979, 134:382-389.

25. Simpson GM, Angus JW: A rating scale for extrapyramidal side effects. Acta Psychiatr Scand Suppl 1970, 212:11-19.

26. Guy W: ECDEU Assessment manual for psychopharmacology, revised. Rockville, MD: US Department of Health, Education, and Welfare; 1976, Publication ADM 76-338.

27. American Psychiatric Association: Diagnostic and Statistical Manual of Mental Disorders. Washington, DC: American Psychiatric Association; Fourth 1994.

28. Heinrichs DW, Hanlon TE, Carpenter WT Jr: The Quality of Life Scale: an instrument for rating the schizophrenic deficit syndrome. Schizophr Bull 1984, 10:388-398.

29. Marder SR, Davis JM, Chouinard G: The effects of risperidone on the five dimensions of schizophrenia derived by factor analysis: combined results of the North American trials. J Clin Psychiatry 1997, 58:538-546.

30. Ward JH: Hierarchical grouping to optimize an objective function. $J$ Amer Statistical Assoc 1963, 58:236-244.

31. Levine SZ, Rabinowitz J: Trajectories and antecedents of treatment response over time in early-episode psychosis. Schizophr Bull 2010, 36:624-632.

Pre-publication history

The pre-publication history for this paper can be accessed here: http://www.biomedcentral.com/1471-244X/11/143/prepub

doi:10.1186/1471-244X-11-143

Cite this article as: Cuyún Carter et al: Sustained favorable long-term outcome in the treatment of schizophrenia: a 3-year prospective observational study. BMC Psychiatry 2011 11:143.

\section{Submit your next manuscript to BioMed Central and take full advantage of:}

- Convenient online submission

- Thorough peer review

- No space constraints or color figure charges

- Immediate publication on acceptance

- Inclusion in PubMed, CAS, Scopus and Google Scholar

- Research which is freely available for redistribution

Submit your manuscript at www.biomedcentral.com/submit
C Biomed Central 